Original Research Article

\title{
Utilisation of antimicrobial agents in intensive care unit at a tertiary care teaching hospital in eastern India
}

\author{
Rajendra Kumar Panda ${ }^{1}$, P. Ansuman Abhisek ${ }^{2}$, Lalit Mohan Sika ${ }^{3}$, \\ Shweta Supriya Pradhan ${ }^{2}$, Sidharth Srabana Routray ${ }^{4}$, Srikanta Mohanty ${ }^{5}$
}

Department of Pharmacology,

${ }^{1}$ S.C.B. Medical College,

Cuttack, ${ }^{2} \mathrm{MKCGMCH}$,

Berhampur, ${ }^{5} \mathrm{Hi}-\mathrm{Tech}$ Medical

College, Bhubaneswar, Odisha,

India

${ }^{3} \mathrm{DHH}$, Khurda Odisha, India

${ }^{4}$ Department of Anaesthesiology and Crictical Care, SCBMCH,

Cuttack, Odisha, India

Received: 17 July 2019

Accepted: 03 August 2019

*Correspondence to:

Dr. P. Ansuman Abhisek,

Email: ansumanabhisek123

@ gmail.com

Copyright: (C) the author(s), publisher and licensee Medip Academy. This is an openaccess article distributed under the terms of the Creative Commons Attribution NonCommercial License, which permits unrestricted noncommercial use, distribution, and reproduction in any medium, provided the original

\begin{abstract}
Background: Antimicrobial agents (AMAs) are the most frequently used drugs in the intensive care units (ICU) and regular auditing can prevent the development of resistance to AMAs, reduce the cost and incidence of adverse drug reactions. The present study was conducted to assess the drug utilisation pattern by measuring the defined daily dose (DDD) per 100 bed days for the AMAs used and their correlation with the APACHE score II.

Methods: This was a prospective observational study, conducted in the Central ICU of SCB Medical College and Hospital, Cuttack, Odisha for 4 months. Data regarding demographic profile, diagnosis, APACHE II score, microbiologic investigation, length of stay, outcome and utilisation pattern of AMAs assessing anatomic therapeutic chemical (ATC) classification and measuring the antimicrobial consumption index (ACI) equal to DDD per 100 bed days were collected and subjected to descriptive analysis. Multinomial logistic regression model was used to predict probabilities of different possible outcomes of categorically distributed variables and independent variables.

Results: Mean age of study population was $44.70 \pm 14.814$ with male and female ratio of 1.63:1. Septicaemia was the most common cause of admission. AMAs were prescribed to $92.66 \%$ of patients during their stay which constitutes $37.32 \%$ of the total drugs used. The DDD per 100 bed days for the AMAs were 118.59 and ceftriaxone was found to be most frequently used. Patients having higher APACHE II score received more no of AMAs (4.20 \pm 1.30 ). Patients having low APACHE II Scores received less number of antibiotics as compared to patients having higher score.

Conclusions: AMAs were prescribed to $92.66 \%$ patients in the central ICU and there is significant relation between the APACHE II score and number of AMAs prescribed.
\end{abstract}

Keywords: Intensive care unit, Utilisation pattern, Antimicrobial agents, Anatomic therapeutic chemical classification, DDD per 100 bed days, APACHE II score

\section{INTRODUCTION}

Patients admitted to ICU are critically ill with or without multi-organ involvement and are exposed to multiple invasive procedures. Hence, they are at a risk of acquiring serious nosocomial infections and vulnerable to multi drug resistant pathogens. As a result these patients are usually prescribed with multiple broad spectrum antimicrobial agents, which are often empirical and based on physician's choice and prior experiences. ${ }^{1}$
Use of multiple medications in ICU patients with altered pharmacokinetic and pharmacodynamic conditions lead to higher incidence of poor treatment outcome and adverse drug events. Thus evaluation and monitoring of the utilisation pattern of drugs used in ICU is highly essential to enable suitable modification in prescribing pattern to increase the therapeutic benefits and to decrease the adverse drug events.

Utilisation study of drugs is associated with the marketing, distribution, preparation and use of drugs in a 
society with special emphasis on its resulting medical, social and economic consequences. ${ }^{2}$ It is an important tool to study the clinical use of drugs in population and its impact on health care system. ${ }^{3}$ AMAs are the most frequently prescribed drugs in the ICU. ${ }^{4}$ Due to this, the total AMA consumption in ICU is approximately ten times higher than the general hospital wards. ${ }^{5}$ As a result, AMAs used in ICU constitute a major part of the total hospital AMA consumption and cost. ${ }^{6}$

There are limited data regarding utilisation of AMA in ICU from Eastern India. The present study was done with the aim to measure the defined daily dose (DDD) per 100 bed days for the AMA used and to find the correlation between the number of AMAs used and APACHE II score. Outcomes after the ICU stay were also analysed.

\section{METHODS}

This prospective observational study was conducted in the Department of Pharmacology in collaboration with Department of Anaesthesia and Critical Care of S.C.B Medical College \& Hospital, Cuttack, from September 2015 to December 2015. The study population included all patients admitted to Central ICU of the Hospital during the study period.

\section{Inclusion criteria}

All the patients admitted to central ICUs irrespective of age and gender.

\section{Exclusion criteria}

Exclusion criteria were patients who stayed for less than $24 \mathrm{hrs}$; incomplete data of the patient in bed head ticket; diagnosis was not ascertained within first three days of admission; pregnant and lactating women

Data regarding demographic profile, regd. no., date of admission, cause of admission, diagnosis, the APACHE Score II, details of laboratory, microbiological, radiological investigations, length of stay, and outcome of ICU stay was collected from the enrolled patients in a predesigned case record form.

APACHE (acute physiology and chronic health evaluation) is a prognostic scoring system calculated within $24 \mathrm{hrs}$ of admission to ICU which can be used to predict mortality and help family members to make informed decision about their case. The maximum score is 71 and higher scores correspond to severe disease and increased risk of death. ${ }^{7}$ APACHE II score was calculated using Medscape tool. ${ }^{8}$

The number of drugs prescribed, generic name of antimicrobial drugs prescribed, their dose, frequency, route and duration of administration were noted. All patients included in the study were followed up till their discharge from ICU.

The antimicrobial agents were classified according to anatomical therapeutic chemical (ATC) classification system and drug utilisation was measured in DDD per 100 bed days. " DDD is defined as assumed average maintenance dose per day for a drug used for its main indication in adults. ${ }^{9}$ DDD provides a fixed unit of measurement independent of price and formulation. For hospital inpatients, DDD per 100 bed days provide a rough estimate of drug consumption.

$\mathrm{DDD} / 100$ bed days $=\frac{\text { No. of units administered in a given period } \times 100}{\text { DDD of drug } \times \text { No. of days } \times \text { No. of beds } \times \text { occupancy index }}$

Average Bed occupancy $=\frac{\text { Totalinpatient service day sfor a period } \times 100}{\text { Totalinpatient bed count } \times \text { No. of day } \sin \text { the period }}$

DDD was calculated using AMC tool software which was developed with reference to WHO collaborating Centre for drug statistics Methodology and recommended by WHO for calculation of DDD per 100 bed days. ${ }^{10}$ Number of beds in ICU=12 and occupancy index for that period in our ICU was 0.95 . This study protocol was approved by the Institutional Ethical Committee, SCBMCH, Cuttack. Informed written consent was taken from all the patients' attendant.

\section{Statistical analysis}

The data was compiled in Microsoft Excel and The statistical analysis was carried out using the Statistical Package for Social Sciences (SPSS Version 16, IBM, NY, USA). Normality of the data was checked by Shapiro Wilk test. The quantitative data were presented as mean $\pm \mathrm{SD}$ and/or median (IQR). Multinomial logistic regression model was used to predict association between total no. of antibiotics (as dependant variable) with other factors/covariates like age group, gender, diagnosis, length of stay, APACHE Score II (as independent variables). Goodness of fit test and pseudo R square was assessed as well.

\section{RESULTS}

Overall skeleton of the study like recruiment, antibiotics utilization and outcome of study is depicted in Figure 1.

A total of 150 patients were included into the study as per the inclusion \& exclusion criteria. The mean age of the study population was $44.70 \pm 14.8$, with male: female ratio of 1.63:1 (Table 1).

The most frequent cause of admission to ICU was septicaemia 49 (32.66\%) (Table 2). Other causes included Medico legal cases, organo-phosphorous poisoning, hepatic encephalopathy, pyrexia of unknown origin, glioblastoma, dengue shock syndrome; one from each. 


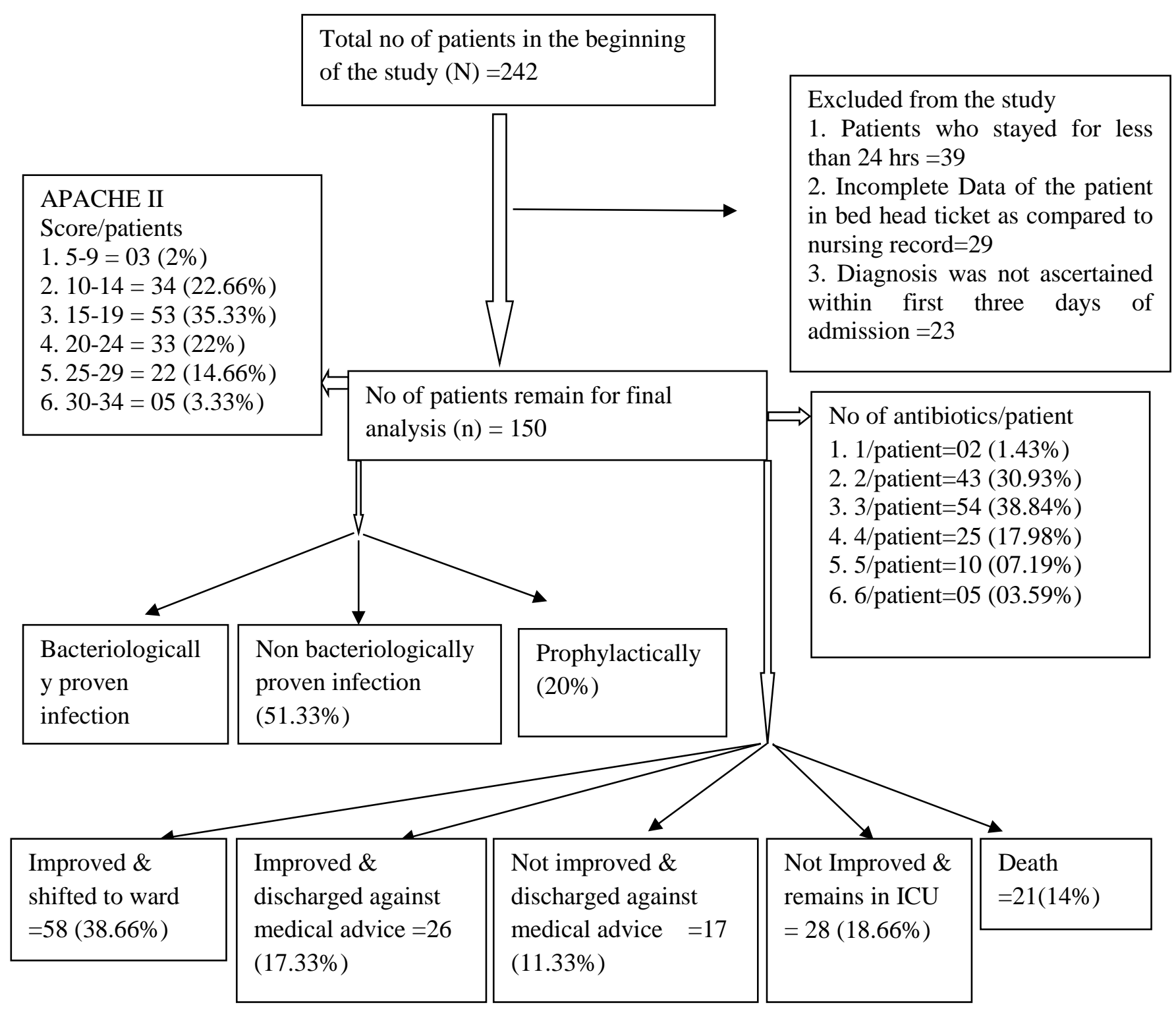

Figure 1: Flow diagram showing recruitment, antibiotics utilization\& outcome of the study.

Table 1: Age and gender distribution of study subjects $(\mathbf{n}=150)$.

\begin{tabular}{|lll|l|}
\hline $\begin{array}{l}\text { Age group } \\
\text { (in years) }\end{array}$ & $\begin{array}{l}\text { Male } \\
(\mathbf{n = 9 3 )}\end{array}$ & $\begin{array}{l}\text { Female } \\
(\mathbf{n = 5 7})\end{array}$ & $\begin{array}{l}\text { Total } \\
(\%)\end{array}$ \\
\hline $\mathbf{1 5 - 3 0}$ & $15(16.12)$ & $10(17.54)$ & $25(16.66)$ \\
\hline $\mathbf{3 1 - 4 0}$ & $24(25.8)$ & $15(26.32)$ & $39(26)$ \\
\hline $\mathbf{4 1 - 5 0}$ & $19(20.43)$ & $13(22.81)$ & $32(21.33)$ \\
\hline $\mathbf{5 1 - 6 0}$ & $19(20.43)$ & $10(17.54)$ & $29(19.33)$ \\
\hline $\mathbf{6 1 - 7 0}$ & $12(12.91)$ & $08(14.03)$ & $20(13.33)$ \\
\hline $\mathbf{7 1 - 8 0}$ & $04(4.31)$ & $01(1.76)$ & $05(3.3)$ \\
\hline Total & $93(62 \%)$ & $57(38 \%)$ & $150(100)$ \\
\hline
\end{tabular}

A total of 1152 drugs were prescribed to 150 patients. These included antimicrobial agents, inotropes, corticosteroids, IV fluids, oxygen, anticholinergics, blood and blood products, etc. A mean of 7.68 drugs were prescribed per patient in ICU. $139(92.66 \%)$ out of 150 patients, received AMAs during their stay. A total of 430 AMAs were prescribed to them, which comprised 37.32\% of the total drugs prescribed. Maximum number of patients i.e. $54(38.84 \%)$ received 3 AMAs followed by $43(30.93 \%)$ who received 2 AMAs (Table 4$)$.

The utilization pattern of AMAs in ICU patients was studied in terms of ATC code, prescription frequency, total units used and ACI (DDD per 100 bed days) (Table 4). Prescription frequency is the number of times the name of the AMA is written and utilisation refers to quantity of drug consumed. Prescription of AMAs per patients was found to be $3.23(2.85 \pm 1.335)$. Twenty different classes of AMAs were used in ICU during the study period as depicted in Table 5. All AMAs were used in injectable form except oral moxifloxacin and 
azithromycin. All AMAs were prescribed in generic name and from the National Essential Drug List of India and Essential drug list of Odisha. All drugs were prescribed in generic name.

Table 2: Cause of admission into ICU.

\begin{tabular}{|ll|}
\hline Clinical conditions & No. of patients (\%) \\
\hline Septicaemia & $49(32.66)$ \\
\hline Post-surgery & $25(16.66)$ \\
\hline Road traffic accident & $22(14.66)$ \\
\hline Respiratory disease & $16(10.66)$ \\
\hline Cardiovascular disease & $12(08.00)$ \\
\hline Neurological disease & $10(06.66)$ \\
\hline Obs \& gyn disease & $10(06.66)$ \\
\hline Others & $06(04.00)$ \\
\hline Total & $150(100)$ \\
\hline
\end{tabular}

Table 3: Number of antimicrobial agents (AMAs) used in patients $(n=139)$.

\begin{tabular}{|lll|}
\hline $\begin{array}{l}\text { Number of } \\
\text { AMAs }\end{array}$ & $\begin{array}{ll}\text { No. of patients } \\
\text { N (\%) }\end{array}$ & Total AMAs \\
\hline One & $02(1.43)$ & 02 \\
\hline Two & $43(30.93)$ & 86 \\
\hline Three & $54(38.84)$ & 162 \\
\hline Four & $25(17.98)$ & 100 \\
\hline Five & $10(07.19)$ & 50 \\
\hline Six & $05(03.59)$ & 30 \\
\hline & $139(100.00)$ & 430 \\
\hline
\end{tabular}

It was observed that total DDD per 100 bed days of the AMAs were 148.37. Five highly utilised (quantitatively) AMAs on the present study were ceftriaxone (32.52) followed by metronidazole (18.76), piperacillin + tazobactum (12.07), imipenem+cilastatin (11.84), and teicoplanin (10.59) (Table 4).

Table 4: Utilization pattern of different AMAs in ICU.

\begin{tabular}{|c|c|c|c|c|c|}
\hline S. no & $\begin{array}{l}\text { Antimicrobial } \\
\text { agents }\end{array}$ & ATC code & $\begin{array}{l}\text { Prescription } \\
\text { frequency }\end{array}$ & $\begin{array}{l}\text { Total units } \\
\text { used }\end{array}$ & $\begin{array}{l}\text { DDD per } 100 \\
\text { bed days }\end{array}$ \\
\hline 1 & Ceftriaxone & J01DD04 & 58 & 890 & 32.52 \\
\hline 2 & Metronidazole & J01X D01 & 69 & 770 & 18.76 \\
\hline 3 & Piperacillin+Tazobactam & J01CR05 & 51 & 514 & 12.07 \\
\hline 4 & Imipenem+ Cilastin & J01DH51 & 40 & 324 & 11.84 \\
\hline 5 & Teicoplanin & J01XA02 & 14 & 145 & 10.59 \\
\hline 6 & Amikacin & J01GB06 & 34 & 273 & 9.97 \\
\hline 7 & Linezolid & J01XX08 & 38 & 257 & 9.39 \\
\hline 8 & Cefotaxim & J01DD01 & 19 & 196 & 7.16 \\
\hline 9 & Amoxycillin + Clavulanic Acid & J01CR02 & 23 & 232 & 6.78 \\
\hline 10 & Meropenem & J01DH02 & 26 & 182 & 6.65 \\
\hline 11 & Azithromycin Oral & J01FA10 & 4 & 8 & 4.87 \\
\hline 12 & Tigecycline & J01AA12 & 9 & 96 & 3.5 \\
\hline 13 & Ceftazidime & J01DD02 & 10 & 180 & 3.28 \\
\hline 14 & Moxifloxacin Oral & J01MA14 & 5 & 8 & 2.92 \\
\hline 15 & Vancomycin & J01XA01 & 7 & 128 & 2.33 \\
\hline 16 & Cefipime & J01DE01 & 3 & 48 & 1.75 \\
\hline 17 & Gentamicin & J01GB03 & 4 & 62 & 1.51 \\
\hline 18 & Fluconazole & $\mathrm{J} 02 \mathrm{AC} 01$ & 4 & 31 & 1.13 \\
\hline 19 & Artesuanate* & P01BE03 & 9 & 56 & 0.88 \\
\hline 20 & Clindamycin & J01FF01 & 3 & 39 & 0.47 \\
\hline Total & & & 430 & & 148.37 \\
\hline
\end{tabular}

* DDD per 100 bed days was calculated manually.

Table 5: APACHE II score with respect to number of patients and number of AMA.

\begin{tabular}{|llll|}
\hline Group no. & APACHE II score & No. of patients & No. of AMAs $(\mathrm{Mean} \pm \mathrm{SD})$ \\
\hline $\mathbf{1 .}$ & $\mathbf{0 - 4}$ & - & - \\
\hline $\mathbf{2 .}$ & $\mathbf{5 - 9}$ & 3 & $1.85 \pm 0.69$ \\
\hline $\mathbf{3 .}$ & $\mathbf{1 0 - 1 4}$ & 34 & $2.93 \pm 1.22$ \\
\hline $\mathbf{4 .}$ & $\mathbf{1 5 - 1 9}$ & 53 & $3.07 \pm 0.75$ \\
\hline $\mathbf{5 .}$ & $\mathbf{2 0 - 2 4}$ & 33 & $3.08 \pm 0.86$ \\
\hline $\mathbf{6 .}$ & $\mathbf{2 5 - 2 9}$ & 22 & $3.57 \pm 1.34$ \\
\hline $\mathbf{7 .}$ & $\mathbf{3 0 - 3 4}$ & 5 & $4.20 \pm 1.30$ \\
\hline $\mathbf{8 .}$ & $\mathbf{3 4}$ & - & - \\
\hline
\end{tabular}


Regarding to indication of AMAs, $28.66 \%$ patients were found to have bacteriologically proven infection (BPI) where as in $20 \%$ patients AMAs were used prophylactically and $51.33 \%$ patients were having non bacteriologically proven infection (NBPI). A total 43 samples were collected from tracheal fluid and aspirates, central line tips, Foley's catheter and pus and sent to the Microbiology Department for culture \& sensitivity. The most frequently reported organisms were Klebsiella, Citrobactor (sensitive to amikacin and imipenem+ cilastatin and meropenem) and Pseudomonas (sensitive to linezolid). Klebsiella, Citrobactor, Acetobactor, Pseudomonas were all resistant to piperacillin+ tazobactam.

Median APACHE II score was found to be 18 (Table 5). It was ascertained using multinomial logistic regression that there is significant association between APACHI II score number of antibiotics used. Patients with APACHE II score 5-14 received less of AMAs. From the multinomial logistic regression table (Table 6) it was ascertained that keeping $>2$ antibiotics group as reference, $\leq 2$ antibiotics given to the patients are significantly associated with men as compared to women (Odd's ratio 2.306 and $p$ value 0.022 ), medical conditions as compared to surgical conditions (odd's ratio 0.306, $\mathrm{p}$ value 0.003 ), $\leq 5$ no of days stay (odd's ratio 5.405, $\mathrm{p}=0.012$ ) and APACHE score (Odd's ratio 10.333, $\mathrm{p}=0.000$ ) in unadjusted model. After adjusting dependent with independent variables, only significant association is obtained with APACHE score 5-14 (II, III) having odd's ratio $6.108,(p=0.018)$ which means patients having low APACHE scores received less no of antibiotics as compared to patients having higher a score.

Table 6: Multinomial logistic regression.

\begin{tabular}{|c|c|c|c|c|c|c|c|c|c|c|}
\hline & & & \multicolumn{4}{|c|}{ Unadjusted } & \multicolumn{4}{|c|}{ Adjusted } \\
\hline \multirow{2}{*}{\multicolumn{3}{|c|}{ No. of antibiotics ${ }^{a}$}} & \multirow{2}{*}{$\begin{array}{l}P \\
\text { value }\end{array}$} & \multirow{2}{*}{$\begin{array}{l}\text { Odd's } \\
\text { ratio } \\
{[\operatorname{Exp}(B)]}\end{array}$} & \multicolumn{2}{|c|}{$95 \% \mathrm{CI}$} & \multirow{2}{*}{$\begin{array}{l}P \\
\text { value }\end{array}$} & \multirow{2}{*}{$\begin{array}{l}\text { Odd's } \\
\text { Ratio } \\
{[\operatorname{Exp}(B)]}\end{array}$} & \multicolumn{2}{|c|}{$95 \% \mathrm{CI}$} \\
\hline & & & & & $\begin{array}{l}\text { Lower } \\
\text { bound }\end{array}$ & $\begin{array}{l}\text { Upper } \\
\text { bound }\end{array}$ & & & $\begin{array}{l}\text { Lower } \\
\text { bound }\end{array}$ & $\begin{array}{l}\text { Upper } \\
\text { bound }\end{array}$ \\
\hline \multirow{12}{*}{$\begin{array}{l}\leq \mathbf{2} \\
\text { AMAs }\end{array}$} & \multirow{2}{*}{$\begin{array}{l}\text { Age group } \\
\text { (in years) }\end{array}$} & $\leq 45$ & 0.349 & 0.729 & 0.376 & 1.413 & 0.367 & 0.678 & 0.291 & 1.577 \\
\hline & & $>45$ & & 1 & & & & 1 & & \\
\hline & \multirow{2}{*}{ Gender } & Men & 0.022 & 2.306 & 1.126 & 4.724 & 0.223 & 1.793 & 0.702 & 4.579 \\
\hline & & Women & & 1 & & & & 1 & & \\
\hline & \multirow{2}{*}{ Diagnosis } & Medical & 0.003 & 0.306 & 0.142 & .659 & 0.634 & 0.745 & 0.221 & 2.509 \\
\hline & & Surgical & & 1 & & & & 1 & & \\
\hline & \multirow{3}{*}{$\begin{array}{l}\text { Length of } \\
\text { hospital stay }\end{array}$} & $\leq 5$ days & 0.012 & 5.405 & 1.447 & 20.189 & 0.067 & 4.211 & 0.903 & 19.629 \\
\hline & & 6-10 days & 0.447 & 1.707 & 0.429 & 6.787 & 0.815 & 1.217 & 0.236 & 6.283 \\
\hline & & $>10$ days & & 1 & & & & 1 & & \\
\hline & \multirow{3}{*}{$\begin{array}{l}\text { APACHE II } \\
\text { score }\end{array}$} & $5-14$ & 0.000 & 10.333 & 3.159 & 33.800 & 0.018 & 6.108 & 1.372 & 27.196 \\
\hline & & $15-24$ & 0.149 & 0.493 & 0.189 & 1.287 & 0.073 & 0.349 & 0.111 & 1.102 \\
\hline & & $25-34$ & & 1 & & & & 1 & & \\
\hline
\end{tabular}

The average length of stay in ICU was 5.1 days. Majority of the patients improved with treatment $(55 \%)$. Regarding the outcome of patients during the stay in ICU, mortality rate was $14 \%(21)$ whereas $58(38.66 \%)$ patients were improved and shifted to ward, $26(17.33 \%)$ patients were improved and discharged against medical advice, $17(11.33 \%)$ patients were not improved \& discharged against medical advice and $28(18.66 \%)$ patients were not improved and remains in ICU.

\section{DISCUSSION}

The demographic profile of the patients admitted to central ICU showed male: female was 1.63: 1 with mean age of $44.7 \pm 14.814$. Male predominance was also observed from studies in India. ${ }^{1,10-15}$ Mean age for admission to ICU is less than other studies. ${ }^{1,12,13} 71 \%$ of patients admitted to CICU were from age group 31-50. The reasons for admission of more patients in this age group are, this is the Central ICU and Trauma ICU was under construction. So all critical cases of RTA, septicaemia and post-surgical cases were admitted.

Average length of stay in the ICU was found to be 5.1 days in the present study. Studies conducted by William et al, Patel et al, Amit et al and Pandiamunian et al showed that the average length of stay in ICU were 5.75, $5.65,4.15$ and 9.46 respectively. ${ }^{1,13,17,18}$ The difference observed in length of stay may be due to variation of clinical condition.

The most common indication for admission to ICU was septicaemia, which is similar to the two other studies. ${ }^{1,13}$ Other indications for admission to CICU varies with other studies except RTA which is the third common cause for admission and this is similar to studies of Patanaik et al from Eastern India. ${ }^{15}$ Variation may be due to geographic distribution, availability of ICU beds in different studies and infrastrucure. 
In the present study it was observed that $92.66 \%$ of the total patients received AMAs, which is similar to studies conducted by Patel et al and Patanaik et al, which shows utilisation of AMA in ICU was $94.95 \%$ and $95 \%$ respectively. ${ }^{13,15}$ Similar studies by William et al shows AMAs were prescribed in $95 \%$ of the patient on the date of admission. ${ }^{1}$ In contradiction studies by Biswal et al showed that nearly $62 \%$ patients in a tertiary care ICU in northern India received antibiotics. ${ }^{19}$ Studies from Nepal, Qatar and Turkey showed that AMA utilisation in ICU were $30 \%, 74 \%$ and $57.5 \%$ respectively which was comparatively less. ${ }^{14,20,21}$

In the present study, the mean of the AMAs prescribed was $2.85 \pm 1.331$ and this was more than other studies conducted by William et al, Anand et al, Pattanaik et al and Amit et al. ${ }^{1,12,15,17}$ Mean of the AMAs prescription of different ICUs of Northern India conducted by William A et al, South India conducted by Anand et al, Eastern India conducted by Pattanaik et al and Dehradun conducted by Amit et al were 2.09, 1.73, 2.27 and 1.74 respectively. ${ }^{1,12,15,17}$ Less number of antimicrobial agents use will result in less drug interaction, bacterial resistance and cost. Above findings showed there is wide gap in different ICUs; may be due to clinical condition of the patient and lack of uniform AMA prescribing policy.

\section{Utilisation of total AMAs (DDD per 100 bed days)}

The utilisation of the total AMAs, were found to be 148.37 DDD per 100 bed days which was similar to study conducted by Anand et al from South India (148.97) and more than the study of Williams et al (112.65) from CMC Ludhiana and Shankar (118.2) from Nepal. ${ }^{1,12,14}$ DDD per 100 bed days from other studies conducted in Germany by Meyer et al (133.7) and in Brazil by De Castro et al 124.6 (in 1996) and 83.6 (in 1990) which was lesser as compared to our study. ${ }^{22,23}$ Study from Gujarat conducted by Patel et al shows utilisation of AMA is very less i.e.
36.52 DDD per 100 bed days. ${ }^{13}$ Five most frequently utilised AMAs in our study was ceftriaxone (32.52), metronidazole (18.76), piperacillin + tazobactum (12.07), imipenem+ cilastatin (11.84) and teicoplanin (10.59). The utilisation of Ceftriaxone was highest in our study which was similar to other studies, where utilisation of Ceftriaxone was the highest. ${ }^{1,12}$ Second mostly utilised AMAs in our study was metronidazole which was similar to other studies, where metronidazole was the second most commonly utilised AMAs. ${ }^{1,14}$

After introduction of hospital antibiotic policy, it was observed that there is drastic fall of DDD per 100 bed days from 162.9 to 101.2 in Europe. ${ }^{24}$ This shows regular scrutiny and modification of AMA utilisation policy is highly essential. Reduction in AMAs utilisation means less of medicine expense, minimal drug interaction \& development of resistance and fewer adverse drug reaction.

\section{Most frequently prescribed AMAs}

It was observed that five most frequently prescribed AMAs were metronidazole $(16.04 \%)$ followed by ceftriaxone $(13.48 \%)$, piperacillin + tazobactum $(11.86 \%)$, imipenem + cilastatin $(9.3 \%)$ and linezolid $(8.83 \%)$. Frequently used AMAs constitute $59.51 \%$ of the total AMA prescription, which is similar to the study conducted by Anand et al $(61 \%) .{ }^{12}$ Our findings are similar to two studies conducted by Patel et al and Hedemba et al, where Metronidazole is the most frequently prescribed AMA. ${ }^{13,16}$ Third generation cephalosporin are the most frequently prescribed AMAs in ICUs from different studies. ${ }^{1,11,12,18}$ There are lots of variations in choosing AMAs in different studies, probably due to geographic distribution, infection site, clinical condition and different hospital antimicrobial policy. Comparison of different antibiotics use from different study is shown below.

Table 7: Five most frequently used AMAs in different ICUs.

\begin{tabular}{|c|c|c|c|c|c|c|c|}
\hline $\begin{array}{l}\text { S. } \\
\text { no }\end{array}$ & Present study & Williams et al $^{1}$ & Anand et $a^{12}$ & Patel et $\mathbf{a l}{ }^{13}$ & $\begin{array}{l}\text { Hedamba et } \\
\mathrm{al}^{16}\end{array}$ & $\begin{array}{l}\text { Pandiamunian } \\
\text { et } \mathbf{a l}^{18}\end{array}$ & ${\text { Patil et } \mathbf{a l}^{25}}^{25}$ \\
\hline 1 & $\begin{array}{l}\text { Metronidazol } \\
\text { e }\end{array}$ & Cefoperazone & Ceftriaxone & Metronidazole & Metronidazole & Ceftriaxone & Tobramycin \\
\hline 2 & Ceftriaxone & Metronidazole & $\begin{array}{l}\text { Piperacillin + } \\
\text { Tazobactum }\end{array}$ & Cefotaxime & Ceftriaxone & Ampicillin & Cefuroxime \\
\hline 3 & $\begin{array}{l}\text { Piperacillin } \\
\text { +Tazobactu } \\
\text { m }\end{array}$ & Levofloxacin & Metronidazole & Ceftriaxone & $\begin{array}{l}\text { Amoxycillin }+ \\
\text { Clavulanic acid }\end{array}$ & Metronidazole & Amikacin \\
\hline 4 & $\begin{array}{l}\text { Imepenem+ } \\
\text { Cilastatin }\end{array}$ & Meropenem & $\begin{array}{l}\text { Amoxycillin+ } \\
\text { Clavulanic acid }\end{array}$ & Ampicillin & $\begin{array}{l}\text { Piperacillin+ } \\
\text { Tazobactum }\end{array}$ & $\begin{array}{l}\text { Piperacillin+ } \\
\text { Tazobactum }\end{array}$ & $\begin{array}{l}\text { Cefoperazone+ } \\
\text { Sulbactam }\end{array}$ \\
\hline 5 & Linezolid & Ceftriaxone & Azithromycin & $\begin{array}{l}\text { Crystalline } \\
\text { Penicillin }\end{array}$ & Amikacin & Azithromycin & $\begin{array}{l}\text { Amoxycillin+ } \\
\text { ClavulanicAcid }\end{array}$ \\
\hline
\end{tabular}

\section{No. of AMAs used /patient}

In our study, $98 \%$ of the patients received more than one AMA during their stay in ICU. This is higher in comparison to studies by Anand et al and John et al, where only $57.8 \%$ \& $69 \%$ patients in ICU received one AMA respectively. ${ }^{12,26}$ Study from Danish University Hospital ICU conducted by Hartmann et al, reported that 
majority of the patients were prescribed more than one AMAs. ${ }^{27}$ Studies from German Surgical ICU conducted by Meyer et al, showed $36.7 \%$ patients were treated with one AMA. ${ }^{28}$ In our study $71.2 \%$ patients received 1-3 AMAs which is similar to other studies Vandana and Patanaik et al. ${ }^{11,15}$

\section{AMA as per bacteriologically proven infection (BPI)}

AMAs were prescribed for bacteriologically proven infection (BPI), non-bacteriologically proven infection (NBPI) and for prophylaxis. Present study shows that the use of AMA prophylatically $(20 \%)$ in ICU is more than study by Sankar et al (7.3\%), but less than other studies conducted by Sunil et al $(31 \%)$ and Pandiamunian et al $(23.9 \%) .^{14,15,18}$ For bacteriologically proven infection (28.66\% in our study) is almost similar to other two studies conducted by Sankar e al $(32.2 \%)$ and Sunil et al $(26 \%){ }^{14,15}$ Non bacteriologically proven infection was $51.33 \%$ in our study, is similar to another study conducted by Pandiamunian et al $(52.3 \%){ }^{18}$

\section{APACHE score and no of AMAs}

It was observed that there is significant association between the APACHE II score and number of AMAs used. Patients with APACHE II score (5-14) received less number of AMAs and patients with higher APACHE score received significantly higher number of AMAs. This finding corroborates with the study conducted by Williams et al.

\section{ICU mortality rate}

Mortality rate was found to be $14 \%$ in the present study which was at par with the studies of Anand et al in south india and Shankar et al in Nepal where ICU mortality observed was $12.5 \%$ \& $15.4 \%$ respectively. ${ }^{12,14}$ In our study $28.66 \%$ patients were discharged against medical advice (both after improvement and without improvement) which is very high $(29.99 \%)$ in comparison to the other studies by Anand et al and Biswal et al which showed $4.9 \%$ and $3.8 \%$ respectively. ${ }^{12,19}$

\section{CONCLUSION}

Majority (one-third) of patients were admitted to ICU due to septicaemia. Approximately $92 \%$ of patients received AMA during their ICU stay, which comprised $37.32 \%$ of the total drugs used. Among $92 \%$ of patients, $98 \%$ received more than one AMA while majority $(85 \%)$ received 2 to 4 AMAs. The AMA utilization (ACI) was inversely proportional to the APACHE score II. The total DDD per 100 bed days of the AMAs were 148.37 and the five highly utilised AMAs in the ICU were ceftriaxone, metronidazole, piperacillin+ tazobactam, imipenem+ cilastatin and teicoplanin. Mortality rate was only $14 \%$.
Following Antibiotic stewardship programme judiciously and timely monitoring of this programme by clinical pharmacologist and microbiologist strictly, will definitely reduce the unnecessary and injudicious use of AMAs. Simultaneously Institution specific AMAs protocol preparation, periodic training of the prescribers with increasing adherence and regular auditing to same will definitely decrease the AMAs resistance and cost.

\section{ACKNOWLEDGEMENTS}

The authors are thankful to National Centre for Disease Control (NCDC) and Delhi Society for Rational Use of Drugs (DSPRUD) in partnership with Ministry of Health and Family Welfare and supported by United States Agency for International Development (USAID) to take part in National Workshop on Surveillance of Antibiotic Consumption in Healthcare Facilities using the AMC Tool on $14^{\text {th }}$ Sept 18 at New Delhi.

Funding: No funding sources

Conflict of interest: None declared

Ethical approval: The study was approved by the Institutional Ethics Committee

\section{REFERENCES}

1. Williams A, Mathai AS, Phillips AS. Antibiotic prescription patterns at admission into a tertiary level intensive care unit in Northern India. J Pharm Bioall Sci. 2011;3:531-6.

2. WHO Expert Committee on the Selection of Essential Drugs, 17-21 October 1977 - WHO Technical Report Series, No. 615 (1st WHO Model List of Essential Medicines) Internet. Apps.who.int. Available at: http://apps.who.int/medicinedocs/en/ m/abstract/Js20185en/. Accessed on 27 March 2019.

3. Sachdeva PD, Patel BG. Drug utilization studies Scope and future perspectives. Int J Pharm Biol Res. 2010;1:11-7.

4. Krivoy N, El-Ahal WA, Bar-Lavie Y, Haddad S. Antibiotic prescription and cost patterns in a general intensive care unit. Pharm Pract (Granada). 2007;5:67-73.

5. Røder BL, Nielsen SL, Magnussen P, Engquist A, Frimodt-Moller N. Antibiotic usage in an intensive care unit in a Danish University Hospital. J Antimicrob Chemother. 1993;32:633-42.

6. Marschner JP, Thürmann P, Harder S, Rietbrock N. Drug utilization review on a surgical intensive care unit. Int J Clin Pharmacol Ther. 1994;32:447-51.

7. Knaus WA, Zimmerman JE, Wagner DP, Draper EA, Lawrence DE. APACHE-acute physiology and chronic health evaluation:a physiologically based classification system. Crit Care Med. 1981;9(8):5917.

8. APACHE II Scoring System Internet. reference. medscape.com. Available at: https://reference. medscape.com/calculator/apache-II-scoring-system Accessed on 27 March 2019.

\section{Recommendations}


9. Internet. WHOcc.no. Available at: https://www.whocc.no/filearchive/publications/ 1_2013guidelines.pdf. Accessed on 27 March 2019.

10. Surveillance of Antimicrobial Use Internet. World Health Organization. 2019. Available at: https://www.who.int/medicines/areas/rational_use/A MU_Surveillance/en/. Accessed on 27 May 2019.

11. Vandana AB. Study of Prescribing Pattern of Antimicrobial Agents in Medicine Intensive Care Unit of a Teaching Hospital in Central India. J Assoc Physicians India. 2012;60:20-3.

12. Anand N, Nayak N, Advaitha MV, Thaikattil NJ, Kantanavar KA, Anand S. Antimicrobial agents' utilization and cost pattern in an Intensive Care Unit of a Teaching Hospital in South India. Indian J Crit Care Med. 2016;20:274-93.

13. Patel MK, Barvaliya MJ, Patel TK, Tripathi C. Drug utilization pattern in critical care unit in a tertiary care teaching hospital in India. Int J Crit Illn Inj Sci. 2013;3(4):250-5.

14. Shankar PR, Partha P, Dubey AK, Mishra P, Deshpande VY. Intensive care unit drug utilization in a teaching hospital in Nepal. Kathmandu Univ Med J (KUMJ). 2005;3(2):130-7.

15. Patanaik SK, Pattanayak C, Prasad A, Chauhan AS. Drug utilization pattern in an intensive care unit setting in Eastern India. Int J Basic Clin Pharmacol. 2015;4:1136-41.

16. Hedamba R, Doshi C, Darji NH, Patel B, Kumari V, Trivedi HR. Drug utilization pattern of antimicrobial drugs in intensive care unit of a tertiary care hospital attached with a medical college. Int $\mathbf{J}$ Basic Clin Pharmacol. 2016;5:169-72.

17. Amit GS. Drug use evaluation study in a tertiary care corporate hospital with special reference to use of antibiotics in ICU department. Int J Adv Pharm Biol Chem. 2013;2:179-89.

18. Pandiamunian J, Somasundaram G. A study of prescribing pattern of Antimicrobial agents in the medical intensive care unit of a tertiary care teaching hospital in Puducherry union territory south India. Int J Pharm Pharm Sci. 2014;6(3):235-8.

19. Biswal S, Mishra P, Malhotra S, Puri GD, Pandhi P. Drug utilization pattern in the intensive care unit of a tertiary care hospital. J Clin Pharmacol. 2006;46:94551.

20. Hanssens Y, Ismaeil BB, Kamha AA, Elshafie SS, Adheir FS, Saleh TM. Antibiotic prescribing pattern in a medical intensive care unit in Qatar. Saudi Med J. 2005;26:1269-76.

21. Usluer G, Ozgunes I, Leblebicioglu H. Turkish Antibiotic Utilization Study Group. A multicenter point-prevalence study: Antimicrobial prescription frequencies in hospitalized patients in Turkey. Ann Clin Microbiol Antimicrob. 2005;4:16.

22. Meyer E, Jonas D, Schwab F, Rueden H, Gastmeier P, Daschner FD. Design of a surveillance system of antibiotic use and bacterial resistance in German intensive care units (SARI). Infection. 2003;31:20815.

23. De Castro MS, Pilger D, Ferreira MB, Kopittke L. Trends in antimicrobial utilization in a University Hospital, 1990-1996. Rev Saude Publica. 2002;36:553-8.

24. Peto Z, Benko R, Matuz M, Csullog E, Molnar A, Hajdu E. Results of a local antibiotic management program on antibiotic use in a tertiary intensive care unit in Hungary. Infection. 2008;36:560-4.

25. Patil PH, Kuchake VG, Ajay K, Pitambar D, Surana S. Evaluation of drug utilization especially antimicrobial agent pattern in tertiary care unit hospital. Int J Community Pharm. 2009;2:13-23.

26. John LJ, Devi P, John J, Guido S. Drug utilization study of antimicrobial agents in medical intensive care unit of a tertiary care hospital. Asian J Pharm Clin Res. 2011;4:81-4.

27. Hartmann B, Junger A, Brammen D, Röhrig R, Klasen J, Quinzio L, et al. Review of antibiotic drug use in a surgical ICU:management with a patient data management system for additional outcome analysis in patients staying more than 24 hours. Clin Ther. 2004;26:915-24.

28. Meyer E, Jonas D, Schwab F, Rueden H, Gastmeier P, Daschner FD. Design of a surveillance system of antibiotic use and Bacterial resistance in German intensive care units (SARI). Infection. 2003;31:20815.

Cite this article as: Panda RK, Abhisek PA, Sika LM, Pradhan SS, Routray SS, Mohanty S. Utilisation of antimicrobial agents in intensive care unit at a tertiary care teaching hospital in eastern India. Int $\mathbf{J}$ Basic Clin Pharmacol 2019;8:1951-8. 